\title{
$17 p$ deletion strongly influences rituximab elimination in chronic lymphocytic leukemia
}

\author{
Cristina Bagacean ${ }^{1,2,3^{*}}$ D , Adrian Tempescul ${ }^{1,2}$, David Ternant ${ }^{4}$, Anne Banet $^{2}$, Nathalie Douet-Guilbert ${ }^{5}$, \\ Anne Bordron ${ }^{1}$, Boutahar Bendaoud ${ }^{3}$, Hussam Saad ${ }^{2}$, Mihnea Zdrenghea ${ }^{6}$, Christian Berthou ${ }^{1,2}$, \\ Gilles Paintaud ${ }^{4}$ and Yves Renaudineau ${ }^{3}$
}

\begin{abstract}
Chronic lymphocytic leukemia (CLL) is the most common type of leukemia and the anti-CD20 monoclonal antibody, rituximab, represents the therapeutic gold standard for more than 2 decades in this pathology, when used in combination with chemotherapy. However, some patients experience treatment resistance or rapid relapses, and in particular, those harboring a 17p/TP53 deletion (del(17p)). This resistance could be explained by a chemo-resistance, but it could also result from the direct impact of del(17p) on the pharmacokinetics of rituximab, which represents the aim of the present study. Accordingly, 44 CLL patients were included in the study, and among them 9 presented a del(17p). Next, a total of 233 rituximab sera were selected for a pharmacokinetic study and analyzed in a two-compartment model showing important differences when del(17p) CLL patients were compared with non-del(17p) patients treated with rituximab and chemotherapy: (1) clearance of rituximab was faster; (2) central volume of rituximab distribution V1 (peripheral blood) was reduced while peripheral volume V2 (lymphoid organs and tissues) was increased; and (3) the rate of rituximab elimination (Kout) was faster. In contrast, the group with a better prognosis harboring isolated del(13q) presented a slower rate of elimination (Kout). Pharmacokinetic parameters were independent from the other factors tested such as age, sex, chemotherapy regimen (fludarabine/cyclophosphamide versus bendamustine), IGHV mutational status, and FCGR3A 158VF status. In conclusion, this study provides an additional argument to consider that del(17p) is effective not only to control chemoresistance but also monoclonal antibody activity, based on higher rituximab turnover.
\end{abstract}

Keywords: Chronic lymphocytic leukemia, Anti-CD20 monoclonal antibody, Rituximab, Pharmacokinetics, Clearance, $17 p$ deletion

\section{Introduction}

In chronic lymphocytic leukemia (CLL), deletion (del) of the short arm of chromosome 17 (17p13) is found in 5 to $8 \%$ of patients requiring first-line treatment and is associated with rapid disease progression as well as a poor response to treatment with a median overall survival (OS) of 2 to 3 years from the time of first-line

\footnotetext{
* Correspondence: cristina.bagacean@univ-brest.fr

'U1227 B Lymphocytes and Autoimmunity, University of Brest; INSERM; networks IC-CGO and REpiCGO from "Canceropole Grand Ouest", Brest, France

${ }^{2}$ Department of Hematology, Brest University Medical School Hospital, 5 Foch Avenue, BP 824, F-29609 Brest, France

Full list of author information is available at the end of the article
}

treatment [1-3]. Such an unfavorable prognosis has been attributed to the critical role played by TP53 on the apoptosis process control, and by halting the cell cycle to allow time for the DNA-repair system to catch up. Such an effect is reinforced by the observation that more than $80 \%$ of patients with CLL carrying del(17p) in one allele have a TP53 mutation on the remaining second allele, leading to complete loss of TP53 protein function. Moreover, 4 to 5\% of CLL cases carry a TP53 mutation in the absence of del(17p), shortening the progression-free survival (PFS) and OS, similar to that seen in cases with del(17p) [4]. As a consequence, and in order to spare patients from ineffective treatment regimens, fluorescent in situ hybridization (FISH) for $17 \mathrm{p} 13$

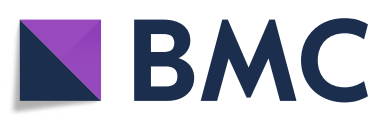

(c) The Author(s). 2019 Open Access This article is distributed under the terms of the Creative Commons Attribution 4.0 International License (http://creativecommons.org/licenses/by/4.0/), which permits unrestricted use, distribution, and

reproduction in any medium, provided you give appropriate credit to the original author(s) and the source, provide a link to the Creative Commons license, and indicate if changes were made. The Creative Commons Public Domain Dedication waiver (http://creativecommons.org/publicdomain/zero/1.0/) applies to the data made available in this article, unless otherwise stated. 
and TP53 mutational analysis have been adopted into routine clinical diagnostics before treatment-initiation and at relapse.

Literature is also growing on the premise that TP53 affects the response to immunotherapy in a large panel of tumors [5-7]. The best studied monoclonal antibody $(\mathrm{mAb})$ affected by the TP53 status is rituximab (RTX) an anti-CD20 mAb that improves patient outcome in B-cell malignancies, and it has been confirmed that CD20 is an important target in CLL [8]. Until recently, the gold standard in CLL treatment was based on the combination of RTX with chemotherapy (fludarabine and cyclophosphamide or bendamustine), but real progress has been made with the introduction of novel molecules such as key tumor tyrosine kinase inhibitors. Their association with anti-CD20 mAb and better knowledge on the therapeutic resistance mechanisms, including those related to TP53 loss, are works in progress with promising results.

RTX (MabThera ${ }^{\circ}$, Rituxan ${ }^{\circ}$ ) is a chimeric mAb, incorporating a human Kappa constant region, a human IgG1 Fc region plus a murine variable region, which recognizes the human CD20 antigen [9]. Several studies reported high variability among individuals in RTX pharmacokinetics which has been linked to several factors including tumor burden, FCGR3A polymorphism or a defective complement pathway [10-12]. The present study aimed to investigate the influence of TP53 loss on RTX pharmacokinetics in CLL patients.

\section{Study design}

Clinical and biological data were available from 44 patients diagnosed with CLL according to the World Health Organization (WHO) classification between 1996 and 2011 at Brest University Hospital [13]. Consent was obtained from all individuals and the protocol approved by the Ethical Board (ClinicalTrials.gov: NCT03294980; CRB Brest, collection 2008-214), in accordance with the Declaration of Helsinki.

Serum concentrations of RTX were determined before each RTX infusion, as previously described [14]. A total of 233 sera were collected at the time of RTX infusion in patients receiving immunochemotherapy and analyzed using a two-compartment model with (i) non-specific (linear) and (ii) target-mediated (nonlinear) elimination pathways, as previously described [15].

\section{Results and discussion Population}

A total of 44 CLL patients were included in the study. The median age at study entry was 72 years [36-85 years], 23 were male and 21 female and the three Binet stages were represented A $(n=5), \mathrm{B}(n=22)$, and C $(n=$ 17). Twenty-eight patients were treated with a RTX, fludarabine, cyclophosphamide (RFC) regimen, and 17 with a RTX, bendamustine (RB) regimen as first-line therapies. The majority of the patients (40/44 [90.9\%]) included in the study achieved a complete response (CR) and 4 patients, treated with RFC, presented a complete response with an incomplete bone marrow hematological recovery (CRi). None of these 4 patients presented a del(17p). The mean number of treatment courses administered was 5.3 [range 4-6] and 5.2 [4-6] for RFC and RB, respectively. After immuno-chemotherapy, the median follow-up was 55.5 months [24-108 months], median time to relapse (TTR) was 60 months [12 - more than 108 months], and time to second CLL treatment (TST) was 84 months [24 - more than 108 months]. In the group studied, 8 patients presented an isolated $\operatorname{del}(13 \mathrm{q}), 10 \mathrm{pa}-$ tients a trisomy 12,4 a normal caryotype, 7 patients a $\operatorname{del}(11 \mathrm{q})$ and 9 patients a del(17p). FCGR3A-158 V/F and the $I G H V$ mutational status were available for all patients and 16 patients, respectively.

\section{Del(17p)/TP53 and RTX pharmacokinetics}

TP53 loss represents an important negative predictor for response to immunotherapy not only in hematological diseases but also in solid tumors, thus supporting the concept that $\mathrm{mAb}$ pharmacokinetics may be affected by the TP53 status [3]. Accordingly, a well established 2-compartiment model was used showing important differences between CLL patients presenting or not a del(17p): (i) RTX clearance (CL) in del(17p) CLL patients was significantly higher than in non-del(17p) CLL patients (Fig. 1a, median $\mathrm{CL}=0.16 \mathrm{~L} /$ day in $\operatorname{del}(17 \mathrm{p}$ ) CLL versus $0.12 \mathrm{~L} /$ day in the CLL patients presenting other cytogenetic anomalies, $p=0.01$ ). This higher $C L$ is potentially caused by the impaired control of p53 on cell-cycle, apoptosis and RTX capacity to promote immune system recruitment/activation; (ii) V1 was reduced in del(17p) CLL patients which is in relation with the observation that peripheral del(17p) B-CLL cells present a loss of CD20 [16, 17] (Fig. 1c, $p=0.01$ ); (iii) V2 was increased, supporting a more extensive tumor antigen burden available for RTX in the lymphoid organs (Fig. 1d, $p=0.04$ ). This is in relation to the presence of expanded proliferation centers in lymph nodes of patients with TP53 loss [18]; and (iv) Kout which is lower in $\operatorname{del}(17 \mathrm{p})$ CLL patients $(p=0.0004)$ suggesting a more rapid RTX elimination in these patients (Fig. 1b).

\section{Other parameters}

In order to complete the pharmacokinetic analysis we next integrated the data concerning age, sex, body surface area (BSA), the traditional staging system Binet, treatment protocol, tumor burden (lymphocytosis, lymphoadenopathy areas), cytogenetic aberrations, mutational status of the IGHV, and FCGR3A status (Table 1). 


\section{A}

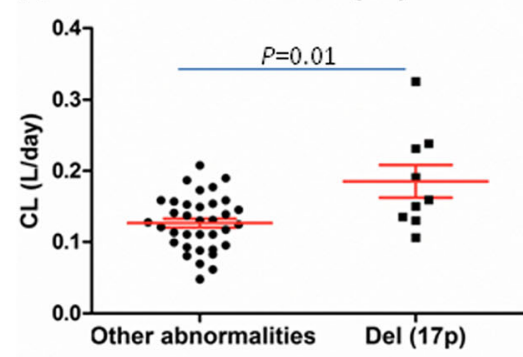

C

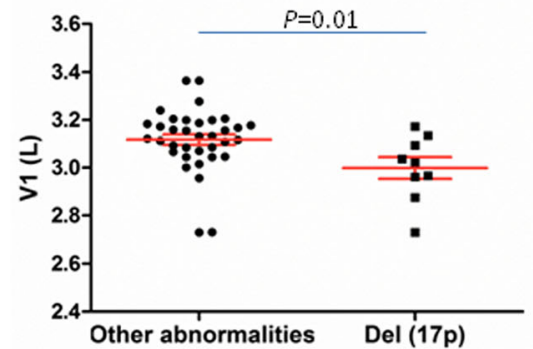

B Rituximab-independent target death (Kout )

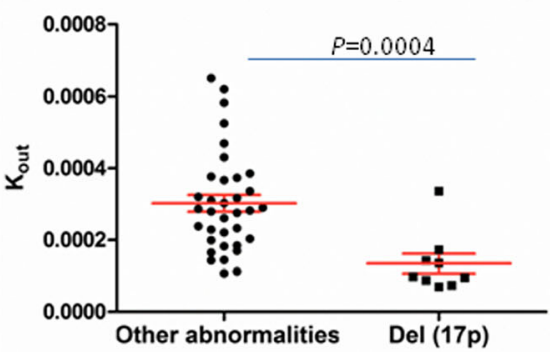

D

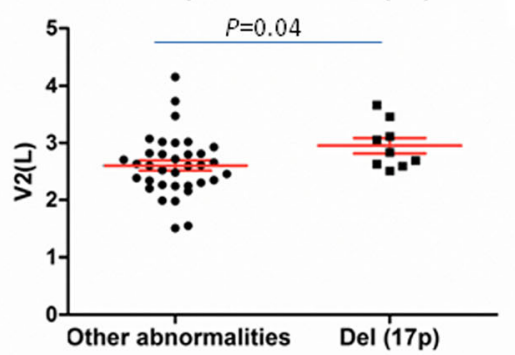

Fig. 1 Del(17p) influences the pharmacokinetics of rituximab (RTX). Del(17p) CLL patients have a faster rituximab (RTX) clearance (CL) (a), a lower RTX distribution in the central volume (V1) (c) while peripheral volume (V2) was larger (d), and a significantly lower RTX rate of elimination (Kout) (b) compared to patients presenting other cytogenetic abnormalities. Statistics are indicated when $p<0.05$ (Mann-Whitney $U$ test)

Table 1 Univariate analysis of pharmacokinetic parameters and biological or clinical variables

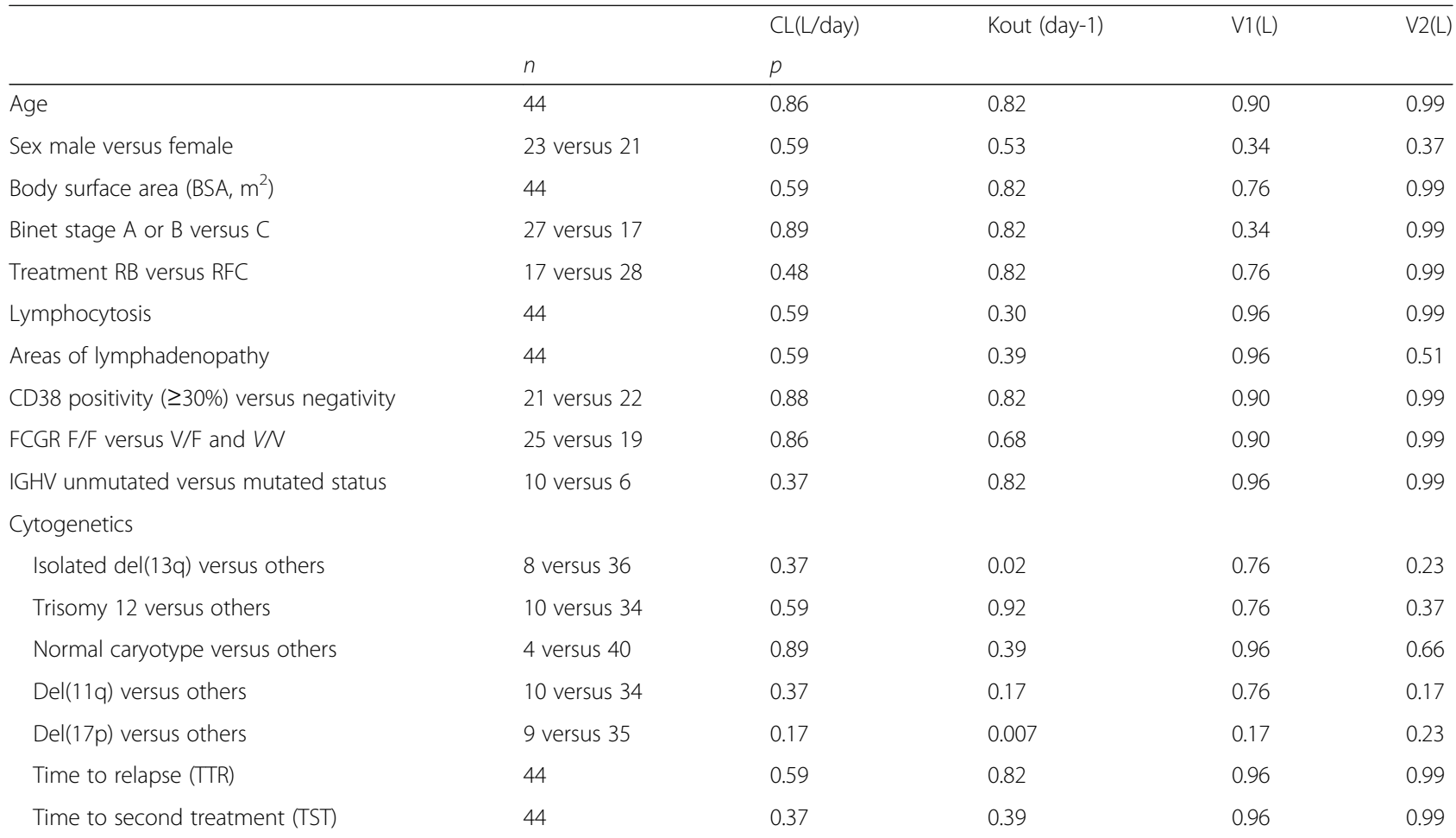

vs. versus, $C L$ clearance, Kout first-order rate constant of rituximab independent death of latent target antigen, $V 1$ central distribution volume, V2 peripheral distribution volume, $R B$ rituximab bendamustine, $R F C$ rituximab fludarabine cyclophosphamide, FCGR Fc gamma receptor, IGHV immunoglobulin heavy chain variable region. Values were adjusted for multiple testing using the Benjamini-Hochberg method (https://www.sdmproject.com/utilities/?show=FDR), and $p<0.05$ considered as significant 
After adjustment for multiple testing using the Benjamini-Hochberg method, significant differences concern Kout, that was decreased in CLL patients harboring a $\operatorname{del}(17 p)(p=0.007)$. Interestingly, for CLL patients with isolated del(13q), and referred as patients with good therapeutic response, the Kout was significantly increased $(p=0.02)$. Both $\operatorname{del}(17 \mathrm{p})$ and $\operatorname{del}(13 \mathrm{q})$ control apoptosis, but differences are related to the cell cycle control, and the capacity to activate the immune system which are both affected by the loss of TP53. Moreover, in non-del(17p) CLL patients, the absence of an association between FCGR3A genotypes and pharmacokinetic parameters further reinforces complement instead of Fc gamma dependent mechanisms for RTX elimination in CLL. This assertion is supported by a recent report showing the potential implication of TP53 loss in complement activation control $[12,19,20]$.

\section{Conclusions}

Our study supports the hypothesis that $\operatorname{del}(17 \mathrm{p}) / \mathrm{TP} 53$ is not only important in protecting tumor cells from DNA damaging agents such as fludarabine and bendamustine but is also important for controlling RTX pharmacokinetics. Accordingly, this study provides an explanation for the RTX resistance observed in CLL patients presenting a $\operatorname{del}(17 p)$ [3]. Further studies are now needed to test whether this effect is restricted to RTX in order to propose a more efficient anti-CD20 mAb in association with specific $B$ cell inhibitors at treatment initiation in patients with del(17p) or TP53 mutations. Treatment of CLL patients with a deficient TP53 requires compounds that promote cell death independently of TP53. Two mAbs have this potential: obinituzimab, a glycocoengineered type-II anti-CD20 mAb, and alemtuzumab, an anti-CD52 which is no longer licensed for treatment of CLL. Another option is to reverse the capacity of the TP53 deficient tumor cells to control the immune system as highlighted by the success of the anti-PDL1 mAb in neoplastic B-cells from Richter syndrome (80\% TP53 deletion/mutation). In Richter syndrome, TP53 loss induces PD-1 expression, explaining the higher expression of PD-1 in these patients and the higher efficacy of the anti-PDL1 mAb $[21,22]$.

\section{Acknowledgements}

Authors express their thanks to Dr. Wesley H. Brooks (University of South Florida, USA) for the editorial assistance and to Simone Forest and Genevieve Michel for the secretarial assistance.

\section{Funding}

This work has been partially supported by the Ligue Contre le Cancer Departmental Committees of Finistere, Ille de Vilaine and Maine et Loire, and data collection was supported by Roche.

\section{Availability of data and materials}

The datasets used and/or analyzed during the current study are available from the corresponding author upon reasonable request.

\section{Authors' contributions}

$\mathrm{CBa}, \mathrm{AT}$ and $\mathrm{YR}$ designed the study. $\mathrm{CBa}, \mathrm{BB}$ and $\mathrm{ABo}$ performed the research. NDG performed the cytogenetic studies. $\mathrm{CBa}, \mathrm{MZ}$ and $\mathrm{ABa}$ performed the clinical data gathering. AT, HS, and CBe took care of the patients and validated clinical data accuracy. CBa, DT, GP and YR analyzed the data. CBa and YR prepared the initial draft. The final manuscript was read and approved by all authors.

\section{Ethics approval and consent to participate}

Consent was obtained from all individuals and the protocol approved by the Ethical Board (ClinicalTrials.gov: NCT03294980; CRB Brest, collection 2008-

214), in accordance with the Declaration of Helsinki.

\section{Consent for publication}

Not applicable.

\section{Competing interests}

The authors declare that they have no competing interests.

\section{Publisher's Note}

Springer Nature remains neutral with regard to jurisdictional claims in published maps and institutional affiliations.

\section{Author details}

'U1227 B Lymphocytes and Autoimmunity, University of Brest; INSERM; networks IC-CGO and REpiCGO from "Canceropole Grand Ouest", Brest, France. ${ }^{2}$ Department of Hematology, Brest University Medical School Hospital, 5 Foch Avenue, BP 824, F-29609 Brest, France. ${ }^{3}$ Laboratory of Immunology and Immunotherapy, Brest University Medical School Hospital, Brest, France. ${ }^{4}$ University of Tours, EA 7501 Innovation and Cell Targeting Group, CHRU de Tours, Laboratory of Pharmacology-Toxicology, Tours, France. ${ }^{5}$ Laboratory of Cytogenetics, Brest University Medical School Hospital, Brest, France. ${ }^{6 " I u l i u ~ H a t i e g a n u " ~ U n i v e r s i t y ~ o f ~ M e d i c i n e ~ a n d ~ P h a r m a c y, ~}$

Cluj-Napoca, Romania.

Received: 2 November 2018 Accepted: 13 January 2019

Published online: 29 January 2019

\section{References}

1. Grever MR, Lucas DM, Dewald GW, Neuberg DS, Reed JC, Kitada S, et al. Comprehensive assessment of genetic and molecular features predicting outcome in patients with chronic lymphocytic leukemia: results from the US intergroup phase III trial E2997. J Clin Oncol. 2007;25(7):799-804.

2. Catovsky D, Richards S, Matutes E, Oscier D, Dyer M, Bezares RF, et al. Assessment of fludarabine plus cyclophosphamide for patients with chronic lymphocytic leukaemia (the LRF CLL4 trial): a randomised controlled trial. Lancet. 2007;370(9583):230-9.

3. Hallek M, Fischer K, Fingerle-Rowson G, Fink AM, Busch R, Mayer J, et al. Addition of rituximab to fludarabine and cyclophosphamide in patients with chronic lymphocytic leukaemia: a randomised, open-label, phase 3 trial. Lancet. 2010;376(9747):1164-74

4. Zenz T, Eichhorst B, Busch R, Denzel T, Habe S, Winkler D, et al. TP53 mutation and survival in chronic lymphocytic leukemia. J Clin Oncol. 2010;28(29):4473-9.

5. Eskelund CW, Dahl C, Hansen JW, Westman M, Kolstad A, Pedersen LB, et al. TP53 mutations identify younger mantle cell lymphoma patients who do not benefit from intensive chemoimmunotherapy. Blood. 2017;130(17): 1903-10.

6. Xiao W, Du N, Huang T, Guo J, Mo X, Yuan T, et al. TP53 mutation as potential negative predictor for response of anti-CTLA-4 therapy in metastatic melanoma. EBioMedicine. 2018:32:119-24.

7. Dong ZY, Zhong WZ, Zhang XC, Su J, Xie Z, Liu SY, et al. Potential predictive value of TP53 and KRAS mutation status for response to PD-1 blockade immunotherapy in lung adenocarcinoma. Clin Cancer Res. 2017;23(12):3012-24.

8. Bagacean C, Zdrenghea M, Tempescul A, Cristea V, Renaudineau Y. Anti-CD20 monoclonal antibodies in chronic lymphocytic leukemia: from uncertainties to promises. Immunotherapy. 2016;8(5):569-81.

9. Reff ME, Carner K, Chambers KS, Chinn PC, Leonard JE, Raab R, et al. Depletion of $\mathrm{B}$ cells in vivo by a chimeric mouse human monoclonal antibody to CD20. Blood. 1994;83(2):435-45. 
10. Cartron G, Dacheux L, Salles G, Solal-Celigny P, Bardos P, Colombat P, et al. Therapeutic activity of humanized anti-CD20 monoclonal antibody and polymorphism in IgG fc receptor FcgammaRIlla gene. Blood. 2002;99(3):754-8.

11. Berinstein NL, Grillo-Lopez AJ, White CA, Bence-Bruckler I, Maloney D, Czuczman M, et al. Association of serum rituximab (IDEC-C2B8) concentration and anti-tumor response in the treatment of recurrent low-grade or follicular non-Hodgkin's lymphoma. Ann Oncol. 1998;9(9):995-1001.

12. Tempescul A, Bagacean C, Riou C, Bendaoud B, Hillion S, Debant M, et al. Ofatumumab capacity to deplete $B$ cells from chronic lymphocytic leukaemia is affected by C4 complement exhaustion. Eur J Haematol. 2016;96(3):229-35.

13. Swerdlow SH, Campo E, Harris NL, Jaffe ES, Pileri SA, Stein H, et al. WHO classification of tumours of haematopoietic and lymphoid tissues: IARC; 2008; p:439:

14. Cornec D, Tempescul A, Querellou S, Hutin P, Pers JO, Jamin C, et al. Identification of patients with indolent $B$ cell lymphoma sensitive to rituximab monotherapy. Ann Hematol. 2012;91(5):715-21.

15. Tout M, Gagez AL, Lepretre S, Gouilleux-Gruart V, Azzopardi N, Delmer A et al. Influence of FCGR3A-158V/F genotype and baseline CD20 antigen count on target-mediated elimination of rituximab in patients with chronic lymphocytic leukemia: a study of FILO group. Clin Pharmacokinet. 2017;56(6):635-47.

16. Tam CS, Otero-Palacios J, Abruzzo LV, Jorgensen JL, Ferrajoli A, Wierda WG, et al. Chronic lymphocytic leukaemia CD20 expression is dependent on the genetic subtype: a study of quantitative flow cytometry and fluorescent in-situ hybridization in 510 patients. Br J Haematol. 2008;141(1):36-40.

17. Zent CS, Taylor RP, Lindorfer MA, Beum PV, LaPlant B, Wu W, et al. Chemoimmunotherapy for relapsed/refractory and progressive 17p13-deleted chronic lymphocytic leukemia (CLL) combining pentostatin, alemtuzumab, and low-dose rituximab is effective and tolerable and limits loss of CD20 expression by circulating CLL cells. Am J Hematol. 2014;89(7):757-65.

18. Garces S, Khoury JD, Kanagal-Shamanna R, Salem A, Wang SA, Ok CY, et al. Chronic lymphocytic leukemia with proliferation centers in bone marrow is associated with younger age at initial presentation, complex karyotype and TP53 disruption. Hum Pathol. 2018;82:215-31.

19. Bordron A, Bagacean C, Mohr A, Tempescul A, Bendaoud B, Deshayes S, et al. Resistance to complement activation, cell membrane hypersialylation and relapses in chronic lymphocytic leukemia patients treated with rituximab and chemotherapy. Oncotarget. 2018;9(60):31590-605.

20. Sebejova L, Borsky M, Jaskova Z, Potesil D, Navrkalova V, Malcikova J, et al. Distinct in vitro sensitivity of p53-mutated and ATM-mutated chronic lymphocytic leukemia cells to ofatumumab and rituximab. Exp Hematol. 2014;42(10):867-74 e1.

21. Behdad A, Griffin B, Chen YH, Ma S, Kelemen K, Lu X, et al. PD-1 is highly expressed by neoplastic B-cells in Richter transformation. Br J Haematol. 2018. ePub ahead of print.

22. Ding W, LaPlant BR, Call TG, Parikh SA, Leis JF, He R, et al. Pembrolizumab in patients with CLL and Richter transformation or with relapsed CLL. Blood. 2017;129(26):3419-27.

\section{Ready to submit your research? Choose BMC and benefit from:}

- fast, convenient online submission

- thorough peer review by experienced researchers in your field

- rapid publication on acceptance

- support for research data, including large and complex data types

- gold Open Access which fosters wider collaboration and increased citations

- maximum visibility for your research: over $100 \mathrm{M}$ website views per year

At $\mathrm{BMC}$, research is always in progress.

Learn more biomedcentral.com/submissions 